\title{
Contrasting xylem vessel constraints on hydraulic conductivity between native and non-native woody understory species
}

\author{
Maria S. Smith ${ }^{1}$, Jason D. Fridley ${ }^{2}$, Jingjing Yin ${ }^{1}$ and Taryn L. Bauerle ${ }^{1 *}$ \\ 1 Department of Horticulture, Cornell University, Ithaca, NY, USA \\ ${ }^{2}$ Department of Biology, Syracuse University, Syracuse, NY, USA
}

Edited by:

Peter J. Melcher, Ithaca College,

USA

\section{Reviewed by:}

Teemu Hölttä, University of Helsinki,

Finland

Qing Ye, Chinese Academy of

Sciences, China

\section{*Correspondence.}

Taryn L. Bauerle, Department of

Horticulture, Cornell University,

134A Plant Sciences Building,

Ithaca, NY 14853, USA

e-mail: bauerle@cornell.edu
We examined the hydraulic properties of 82 native and non-native woody species common to forests of Eastern North America, including several congeneric groups, representing a range of anatomical wood types. We observed smaller conduit diameters with greater frequency in non-native species, corresponding to lower calculated potential vulnerability to cavitation index. Non-native species exhibited higher vessel-grouping in metaxylem compared with native species, however, solitary vessels were more prevalent in secondary xylem. Higher frequency of solitary vessels in secondary xylem was related to a lower potential vulnerability index. We found no relationship between anatomical characteristics of xylem, origin of species and hydraulic conductivity, indicating that non-native species did not exhibit advantageous hydraulic efficiency over native species. Our results confer anatomical advantages for non-native species under the potential for cavitation due to freezing, perhaps permitting extended growing seasons.

Keywords: hydraulic conductivity, xylem anatomy, embolism vulnerability, exotic woody plants, efficiency vs. safety, vessel connectivity

\section{INTRODUCTION}

Wood xylem vessel members constitute the main pathway for water transport over long distances within a plant and are morphologically diverse across species. In addition to the pronounced differences in ring-porous vs. diffuse-porous species, xylem arrangement follows a continuum of organizational levels. Vessel organization and distribution including vessel number and frequency are associated with varying patterns of community assembly and adaptive variation in growth strategies across phylogentic groups (Baas, 1986). Moreover, correlations between wood anatomical traits (e.g., porosity type, variation in bordered pits and perforation types) and factors integrating seasonal water availability may reveal characteristics representing successful plant hydraulic properties such as water-use efficiency, conductivity, and vulnerability to cavitation (Jansen et al., 2004; Taneda and Sperry, 2008) that promote a physiological advantage of non-native over native species (Pratt and Black, 2006; Caplan and Yeakley, 2010).

High relative growth rate (RGR) is common to many introduced non-native woody plants (Dawson et al., 2011). Hydraulic architecture is associated with plant growth rate (Brodribb et al., 2002; Meinzer et al., 2010), with xylem vessel structure and size identified as the main constraints on maximum water transport and thus hydraulic conductivity (Tyree and Ewers, 1991; Steppe and Lemeur, 2007). Woodrum et al. (2003) examined xylem vessel anatomy and hydraulic conductivity of maples (Acer) of varying growth rates but few differences in hydraulic conductivity or anatomical xylem vessel characteristics were apparent. Pratt and Black (2006) were also unable to find differences in cavitation resistance or xylem specific conductivity between five pairs of cooccurring native and non-native trees. However, few if any studies on the relationship between vessel conduit anatomy and water transport in native vs. non-native species have been performed to date. Yet, trends in species' hydraulic conductivity have been broadly categorized by means of xylem conduit diameter and rate of water flow (efficiency; Tyree et al., 1994), and that there exists a positive relationship between vessel diameter (VD) and growth rate.

Plant water-use strategies are often evaluated as functional trade-offs that maximize resource capture and retention rates based on the resident environment (Grime, 2001). Non-native species with invasive potential are considered a threat to native plant communities due to more efficient resource-use (Grotkopp et al., 2002; Funk and Vitousek, 2007; Drenovsky et al., 2012) or higher resource use and capture (Cavaleri and Sack, 2010) such that they effectively out-compete natives in their introduced range (Davis et al., 2000; Drenovsky et al., 2012). One way in which non-natives may increase their efficiency is by decreasing the cost of acquiring or using resources. By investing in cheaper structural tissues (Dale and Causton, 1992), species lose benefits associated with increased construction cost which, in turn, influences species' hydraulic vulnerability to water stress or freezing (Carlquist, 1977). Elucidating the linkage between wood characteristics and water transport provides insight into plant hydraulic functional strategies (Baas, 1986; Taneda and Sperry, 2008).

Embolism vulnerability places a constraint on maximum water transport through a reduction in hydraulic conductance as a consequence of drought and freeze-thaw cycles (Pockman and 
Sperry, 1996; Meinzer et al., 2001) and even normal growth conditions (Cochard and Tyree, 1990; Sperry et al., 1994; McCully et al., 1998). Recent studies have emphasized additional vessel characteristics that are potentially important drivers of hydraulic transport and protection against embolism formation, including inter-vessel pit structure and size as a bottleneck to air-seeding (Jansen et al., 2004; Choat et al., 2008; Christman et al., 2009; Lens et al., 2011), vessel perforation plate type (openings at the end of vessel elements; Jansen et al., 2004), vessel wall thickness (Hacke et al., 2001), and vessel connectivity (Loepfe et al., 2007; Lens et al., 2011). Comparative studies that investigate vessel characteristics over a wide survey of plant species are limited (but see Jansen et al., 2004; McCulloh et al., 2010).

Here we examine the hydraulic properties of 82 native and non-native woody species common to forests of Eastern North America, including several congeneric groups, which represent a range of anatomical wood types. Broad surveys containing a large number of species have the potential to reveal functional classification syndromes that relate to plant productivity (Zanne et al., 2010). Our goal was to compare relationships between hydraulic conductance and theoretical xylem vessel vulnerability by stem vascular structure and arrangement between non-native and native woody species. We examined relationships between stem xylem vessel anatomical arrangement, xylem vessel types, stem specific hydraulic conductivity, wood development/ timing of vessel development, and cavitation vulnerability index among native and non-native woody understory species, as well as differences in water-use efficiency between native and non-native individuals. The use of an index to exam potential stem vulnerability is a useful metric when examining larger data sets that represent several species. Specifically, we tested the hypothesis that non-native understory species have greater capacity for water transport than native understory species.

\section{MATERIALS AND METHODS \\ PLANT MATERIAL AND GROWING CONDITIONS}

Stem material was harvested from mature plants in a common garden comprised of a homogenous, clay loam soil in Syracuse, $\mathrm{NY}$, USA $\left(43^{\circ} 03^{\prime} \mathrm{N}, 76^{\circ} 09^{\prime} \mathrm{W}\right)$, representing a range of native and non-native woody species including several common genera (Table 1). At the time of harvest, individuals were approximately the same size and age and maintained under the same condition. Each species was grown in three replicate blocks, each under $80 \%$ shade cloth during the growing season (late May-late October) to simulate deciduous forest conditions. Species were obtained from natural areas in central New York when possible; those species not available in our region were sourced from commercial growers located in the northern US. Plants were pruned occasionally over the 5-year period preceding stem harvest but not fertilized or watered, and summer wilting was not observed.

\section{HYDRAULIC CONDUCTIVITY AND WUE MEASUREMENTS}

Three terminal branch stems of similar diameter containing 1 year's growth were randomly sampled from individuals of each species from each of three replicate blocks in November 2011. Stems were kept moist in damp paper towels in a cooler $\sim 2 \mathrm{~h}$ prior to taking measurements in a temperature-controlled room at $25^{\circ} \mathrm{C}$, equal to the temperature of the high pressure flow meter (HPFM) (Dynamax Inc., Houston, TX, USA). Diameter and stem length were recorded, and the cortex was shaved from the proximal end of stems prior to attachment to a HPFM.

Stem hydraulic conductance $\left(K_{h}\right)$ was measured directly with the HPFM, using methods described by Tyree et al. (1995). Each measurement was recorded $\sim 30 \mathrm{~s}$ after stems had a visible flow of water through the end of the stem. Conductance $\left(K_{h}, \mathrm{~kg}\right.$ $\left.\mathrm{s} \mathrm{MPa}^{-1}\right)$, the inverse of resistance, was measured by the force of pressurized water through the stem $(P)\left(\mathrm{MPa} \mathrm{m}^{-1}\right)$ and the rate of water flow $(F)\left(\mathrm{Kg} \mathrm{s}^{-1}\right)$. Conductance was calculated as the slope of the regression plot $F$ vs. $P$ :

$$
K_{h}=d F / d P
$$

Stem hydraulic measurements were conducted using quasi-steady state, where $F$ and $P$ are approximately constant (Tyree et al., $1993,1995)$. Specific stem hydraulic conductivity $\left(K_{s}\right)$ was calculated factoring out the variation in stem length and diameter cross-sectional area ( $\mathrm{kg} \mathrm{s} \mathrm{MPa}^{-1} \mathrm{~mm}^{-3}$, Sperry et al., 1988).

Photosynthesis was monitored monthly for each individual at intensities of 800 , and $100 \mathrm{mmol}$ photon $^{-2} \mathrm{~s}^{-1}, 700 \mathrm{mmol}$ $\mathrm{s}^{-1}$ flow rate, $20^{\circ} \mathrm{C}$ (Fridley, 2012). WUE was calculated as the ratio of carbon fixed to water lost, (Li-COR 6400, Inc., Lincoln, NE, USA) (C uptake/transpiration rate, in units of micromol CO2 per mmol H2O).

\section{ANATOMICAL MEASUREMENTS}

Two to three stem segments used for hydraulic conductivity were used for anatomical sectioning following conductivity measurements. In addition, three supplemental stem segments collected from the same plants in November 2010 were also sectioned for anatomical measurements. One $\mathrm{cm}$ long segments in random locations were removed from the stem, immediately preserved in formalin-acetic acid-alcohol solution (FAA), and stored at room temperature until the embedding process. Samples were dehydrated in a series of ethanol-tertiary butanol (TBA) dilutions before infiltration with pure TBA (Ruzin, 1999).

Stem anatomical samples were embedded in successive changes of Paraplast Plus embedding medium (McCormick Scientific, Saint Louis, Missouri, USA) in a $60^{\circ} \mathrm{C}$ drying oven for 2 days. Samples were embedded in a final paraffin change hardened with 15\% (v:v) paramount (Fischer Scientific, Fair Lawn, New Jersey, USA). Transverse cross-sections were cut at $20 \mu \mathrm{m}$ increments using a rotary microtome (HM 355S, Microm International $\mathrm{GmbH}$, Walldorf, Germany). Cross sections were stained with saffranin-O [1\% (w:v) in 50\% ethanol] and counterstained using fast-green $[0.1 \%(\mathrm{w}: \mathrm{v})$ in $1: 1$ absolute ethanol and clove oil] in a series with histo-clear (National Diagnostics, Atlanta, Georgia, USA) to remove paraffin.

Five images per stem were randomly selected for imaging using 20x magnification with a compound light microscope with a fixed camera attachment (Olympus Imaging Corp., Tokyo, Japan). Images representing $0.77 \mathrm{~mm}^{2}$ cross sectional area were first processed through Photoshop (CS5; Adobe Systems Inc., Mountain 
Table 1 | Woody shrub species list tested and attributes.

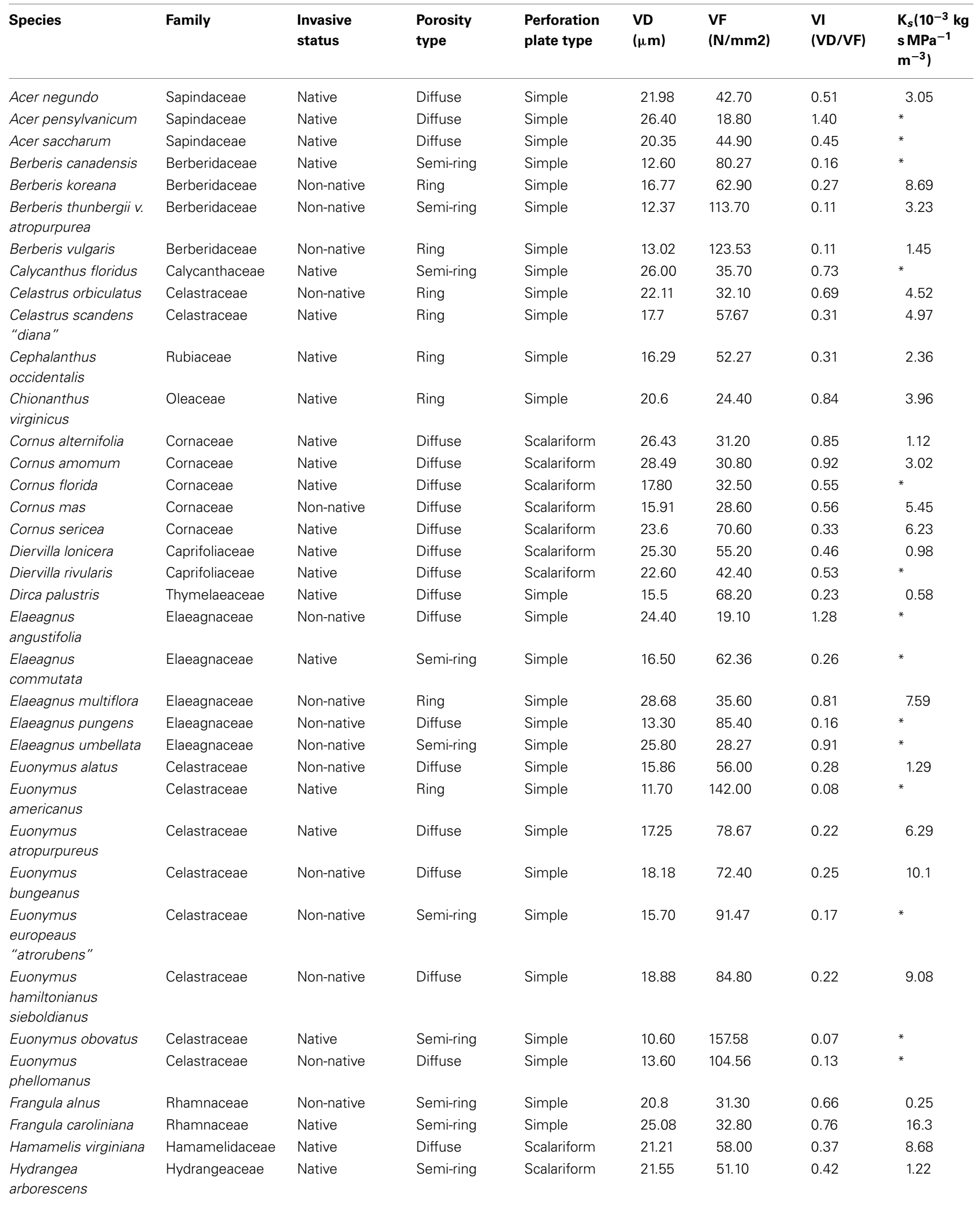


Table 1 | Continued

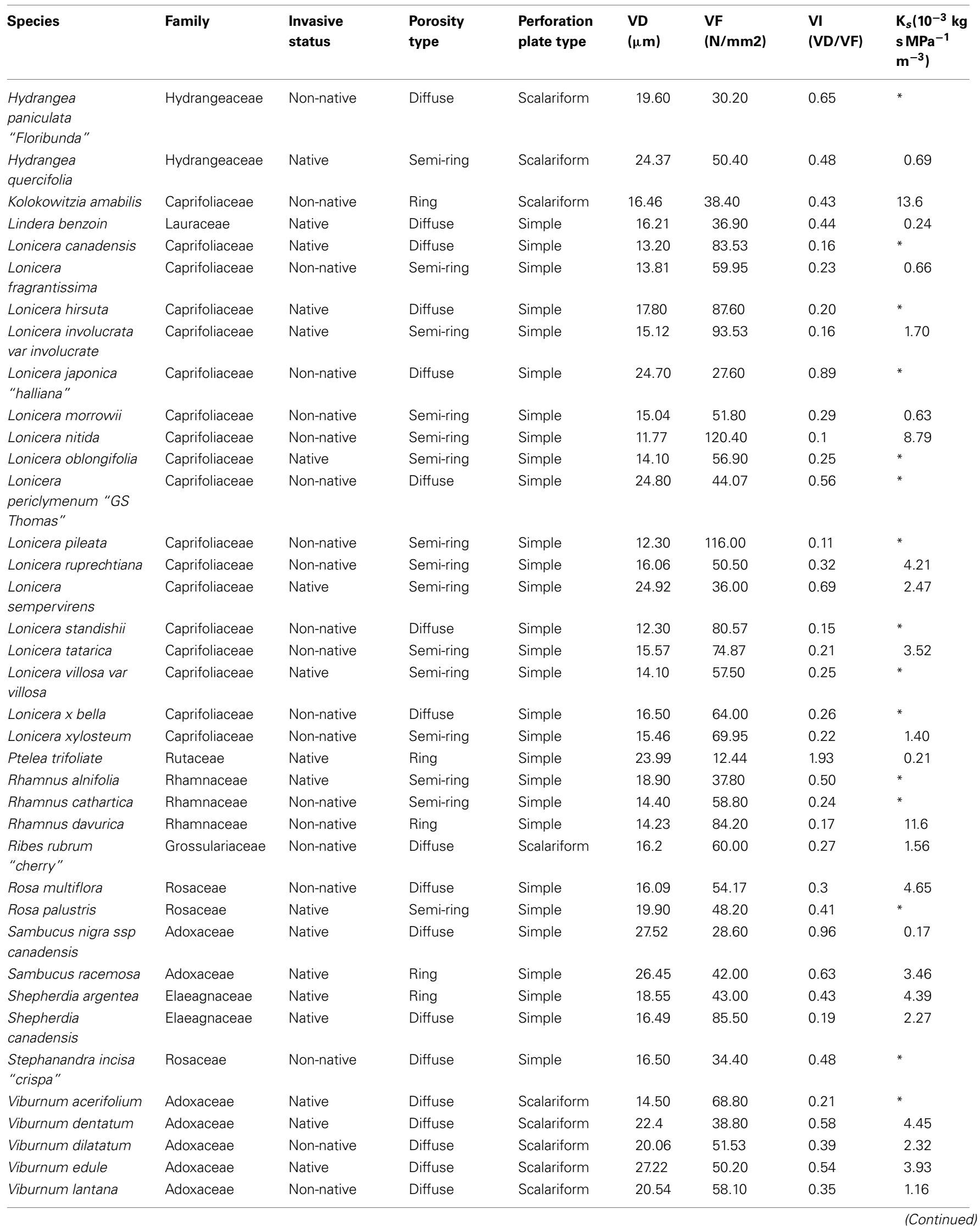


Table 1 | Continued

\begin{tabular}{|c|c|c|c|c|c|c|c|c|}
\hline Species & Family & $\begin{array}{l}\text { Invasive } \\
\text { status }\end{array}$ & $\begin{array}{l}\text { Porosity } \\
\text { type }\end{array}$ & $\begin{array}{l}\text { Perforation } \\
\text { plate type }\end{array}$ & $\begin{array}{l}\text { VD } \\
(\mu \mathrm{m})\end{array}$ & $\begin{array}{l}\text { VF } \\
\text { (N/mm2) }\end{array}$ & $\begin{array}{l}\text { VI } \\
\text { (VD/VF) }\end{array}$ & $\begin{array}{l}\mathrm{K}_{s}\left(10^{-3} \mathrm{~kg}\right. \\
\mathrm{s} \mathrm{MPa}^{-1} \\
\left.\mathrm{~m}^{-3}\right)\end{array}$ \\
\hline Viburnum lentago & Adoxaceae & Native & Diffuse & Scalariform & 22.06 & 51.00 & 0.43 & 2.70 \\
\hline $\begin{array}{l}\text { Viburnum nudum } \\
\text { ssp cassanoides }\end{array}$ & Adoxaceae & Native & Semi-ring & Scalariform & 15.90 & 65.80 & 0.24 & $*$ \\
\hline Viburnum opulus & Adoxaceae & Non-native & Diffuse & Scalariform & 22.10 & 63.50 & 0.35 & $*$ \\
\hline $\begin{array}{l}\text { Viburnum opulus var } \\
\text { Americana }\end{array}$ & Adoxaceae & Native & Diffuse & Scalariform & 19.26 & 71.50 & 0.27 & 4.21 \\
\hline $\begin{array}{l}\text { Viburnum } \\
\text { prunifolium }\end{array}$ & Adoxaceae & Native & Diffuse & Scalariform & 15.00 & 46.70 & 0.32 & * \\
\hline $\begin{array}{l}\text { Viburnum } \\
\text { rafanesquianum }\end{array}$ & Adoxaceae & Native & Diffuse & Scalariform & 16.76 & 66.60 & 0.25 & 26.3 \\
\hline Viburnum setigerum & Adoxaceae & Non-native & Diffuse & Scalariform & 20.20 & 45.60 & 0.44 & $*$ \\
\hline
\end{tabular}

Mean vessel traits, VD, vessel diameter; VF, vessel frequency; VI, vulnerability index; and Ks, stem hydraulic conductivity, for each species.

${ }^{*}$ Denotes species without high pressure flow meter (HPFM) data.

View, CA, USA) to select and fill each individual vessel, and then analyzed for xylem vessel lumen cross sectional area (VA) using the image-analysis software Image J (National Institute of Health, Bethesda, MD, USA, http://rsb.info.nih.gov/ij/index. html). Vessel area was converted to diameter (VD) assuming circularity of vessels. Conduit-containing sections of each image were then randomly cropped to $0.09 \mathrm{~mm}^{2}$ to represent the xylem area of the smallest stem to obtain vessel frequency (VF) over a uniform area for all species. The use of an index can be a valuable metric to examine larger data sets that are compiled of several species to look for generality in vulnerability patterns (Zanne et al., 2010). The potential of vessel vulnerability during water stress was determined using methods from Carlquist (1977) where vulnerability index (VI) $=\mathrm{VD} / \mathrm{VF}$, where VD is vessel diameter $(\mu \mathrm{m})$, and $\operatorname{VF}$ is $\operatorname{VF}\left(\mathrm{N} / \mathrm{mm}^{-2}\right.$ ) (Gonçalves et al., 2007; Bauerle et al., 2011; Aref et al., 2013). To parse seasonal differences in vessel traits and vulnerability, three equal concentric rings were overlaid on the cross section to delineate the first, middle, and last rows of vessels to represent the seasonal transition in vessel development from early to late season. Vessel measurements within the three rings were analyzed using the same method as above. Xylem vessel diameter of all 82 species was classified into seven classes from $<10 \mu \mathrm{m}$ to $>35 \mu \mathrm{m}$ at $5 \mu \mathrm{m}$ intervals. The frequency of each class was estimated.

Vessel groupings were classified into four categories in both metaxylem, the primary xylem that differentiates after the protoxylem and is characterized by broader vessels, and secondary xylem, i.e., the categories of 2, 3, 4, and more than 5 vessels grouped together. The amount of vessel groupings in each classification was counted. For each classification we then calculated grouped vessel percentage (the percentage of the number of vessels grouped relative to the total number of vessels), vessel grouping index (mean number of vessels per vessel grouping), and the percentage of solitary vessels relative to the total number of vessels.

\section{STATISTICAL METHODS}

Differences in the distribution of vessel class frequency were assessed between native and non-native understory species using the Chi-square test. Differences in factors predicting conductivity, vessel traits and vulnerability index were tested using mixedeffect models to control for variability from genus classification. A bivariate regression analysis tested for significance in relationships between conductivity and vessel traits, where conductivity and vulnerability index were log-transformed to improve the assumption of normality. A linear 90th quantile regression was performed using the "quantreg" package from R (v. 2.13.1) to estimate the slope of the "packing limit" of vessels, representing the upper limit of the number of vessels that can fit in a given area based on size. Forty-nine of the 82 species, those with conductivity measurements, were analyzed for significance in VD over three distinct rows of xylem vessels, representing three different periods of annual wood formation (the first, middle and last row of selected vessels). A linear mixed model was constructed to determine how time influences vessel sizes between porosity type, origin, and perforation plate type. Genus was included as a random variable, and vessel row was used as an interaction term for time across effects. Vessel grouping in metaxylem was only compared between non-native and native species that had metaxylem using the Mann-Whitney $U$-test. Each classification of vessel grouping in secondary xylem was compared, respectively between non-native and native species using One-Way analysis of variance (ANOVA). Data were tested for normality and homogeneity to determine if it matched the assumptions of ANOVA. A mixed effects model was used to test for significant predictors of water use efficiency (WUE), using origin and differing light levels across 38 of the 82 species. Species was used as random factor, due to non-independence of repeated measures. Tukey's HSD post-hoc analysis was performed to distinguish differences between light levels. The relationships between vulnerability index and vessel groupings traits were examined individually by linear regression. All analyses excluding quantile regression were performed using JMP (SAS Institute Inc., Cary, NC, v. 10.0). 


\section{RESULTS}

Of the 82 species studied, porosity type did not differ with origin $(P=0.970)$. When species were separated by porosity type, $55.3 \%$ of native species had a diffuse porous xylem ring structure, $29.8 \%$ had a semi-ring, and $14.9 \%$ had a ring porous vessel. Non-native species had a distribution comprised of $52.6 \%$ diffuse porous, $31.6 \%$ semi-ring porous, and $15.8 \%$ ring porous. However, contributions of some overrepresented genera drove much of the porosity type distribution. When accounting for genus, members of Viburnum and Lonicera comprised $\sim 37 \%$ of the total individuals, with most species within a genus sharing similar perforation plate type and porosity type traits (Table 1).

\section{VESSEL SIZE DISTRIBUTION}

The distribution of vessel class frequency differed between native and non-native species $(P<0.0001$, Figure 1$)$. Vessels with diameters less than $20 \mu \mathrm{m}$ appeared more frequently in nonnative species than native species. The diameter of more than $50 \%$ of the vessels in non-native species ranged from 10 to $20 \mu \mathrm{m}$, in which $33.9 \%$ of the vessels had diameters between 10 and $15 \mu \mathrm{m}$. Frequency of the vessels with diameters more than $20 \mu \mathrm{m}$ was higher in native species than non-native species. The diameter of more than $70 \%$ of the vessels in native species ranged uniformly from 10 to $25 \mu \mathrm{m}$, with the $15-20 \mu \mathrm{m}$ interval class having the highest VF, $26.1 \%$.

\section{HYDRAULIC CONDUCTIVITY $\left(K_{s}\right)$}

The mixed-effects model did not show any effects from porosity, perforation plate or status as native or non-native on hydraulic conductivity $(P>0.10)$.

\section{VESSEL TRAITS AND VULNERABILITY INDEX}

No differences in VD, VF, or VI were found across porosity type, origin or perforation plate type $(P>0.10$, Table 3$)$. Despite an insignificant difference, non-native species had lower log VI $(-0.978 \pm 0.167)$ compared with native species $(-0.880 \pm$

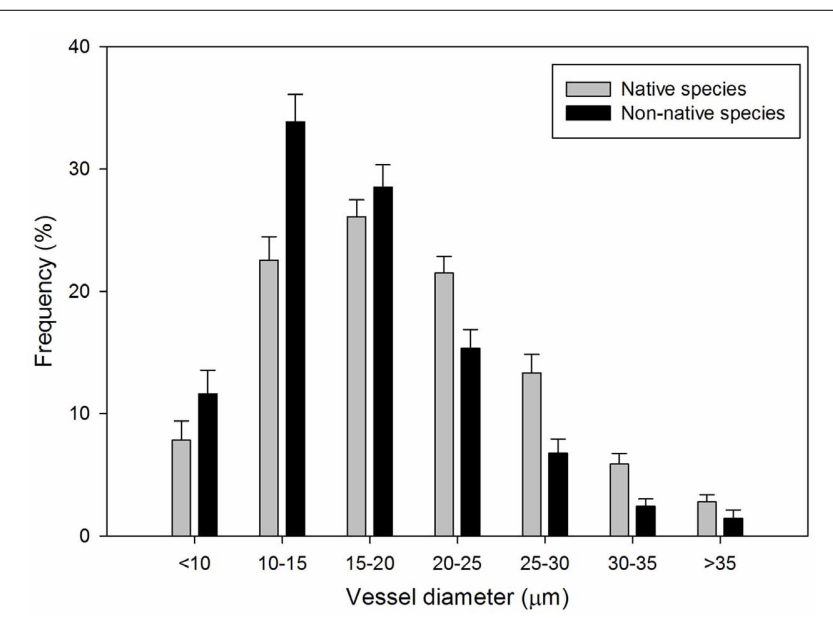

FIGURE 1 | Frequency distribution of xylem vessel diameter $(\mu \mathrm{m})( \pm 1$ $S E$ ) for 52 native (gray bars) and non-native (black bars) woody shrub species.
0.141), which was the result of a lower but significant VD of non-native species at $\alpha=0.10(P=0.0694)$. Overall, non-native species had smaller vessels and an overall lower vulnerability index.

\section{RELATIONSHIPS BETWEEN VD, VF, VI, VESSEL AREA AND $\mathrm{K}_{\boldsymbol{s}}$}

A positive relationship was observed between log-transformed vessel area and log-transformed hydraulic conductivity $(P=$ 0.033 , Figure 2 ). This indicates faster water movement in species with a higher number of vessels per xylem area than those with less vessel area per unit xylem area (Figure 3). There was no correlation between $\mathrm{K}_{s}$ and VI $(P=0.6677$, Figure 3$)$. When VI was divided into the individual components of VD and VF to test for a relationship with $K_{s}$, no relationship was found for either VD $(P=0.3565)$ or $\operatorname{VF}(P=0.380)$.

\section{VESSEL PACKING}

Overall, an inverse relationship between VD and VF was found for both native and non-native species (Figure 4), indicating the larger the conduit diameter, the fewer number of conduits that can occupy a given area of wood. The slope of the constraint line for native species $(-6.382)$ was steeper than the slope for non-native species $(-4.909)$.

\section{TIMING OF FORMATION AND INFLUENCE ON VESSEL SIZE}

Genera explained 39\% of the total variability within the model $(P<0.10)$, suggesting that variation among genera contributes to differences in VD. Timing of vessel development was a significant factor $(P<0.001)$. In a comparison of vessel rows, the last row of vessels was significantly smaller than that of both the first and middle rows $(P<0.10$, Table 2$)$. No interaction was detected between timing of vessel development and porosity, perforation plate type, or origin $(P>0.10)$. Only origin had an effect on VD $(P<0.001)$. Porosity type and perforation plate type had no predictive effect on VD (Table 3 ). The variability contributed by

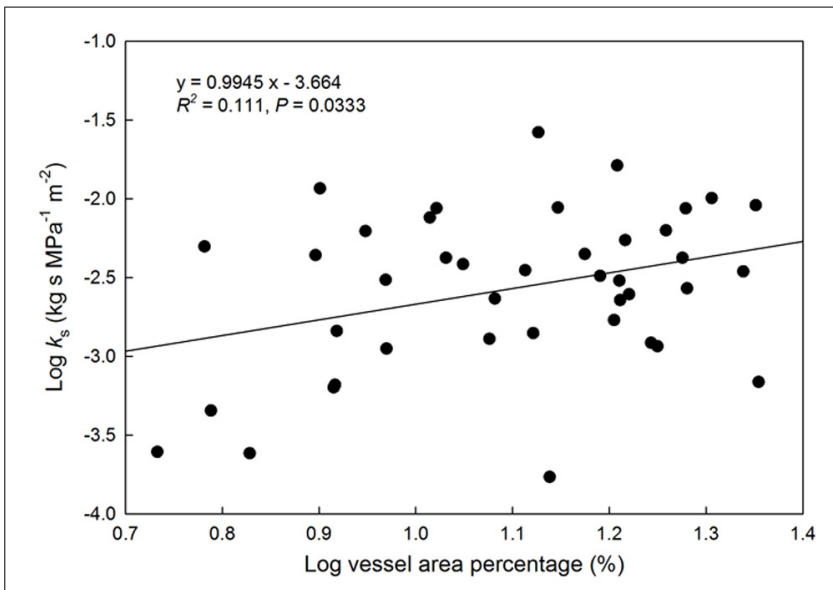

FIGURE 2 | Relationship between log(vessel area) as a percentage of the total viewing area vs. hydraulic conductivity ( $\mathrm{kg} \mathrm{s} \mathbf{M P a}^{-1} \mathbf{m}^{-2}$ ). Solid line represents the line of best fit $\left(\log \left[K_{s}\right]=0.095(\log [\right.$ vessel area \%]) + 3.66). Points represent species with available HPFM data. 


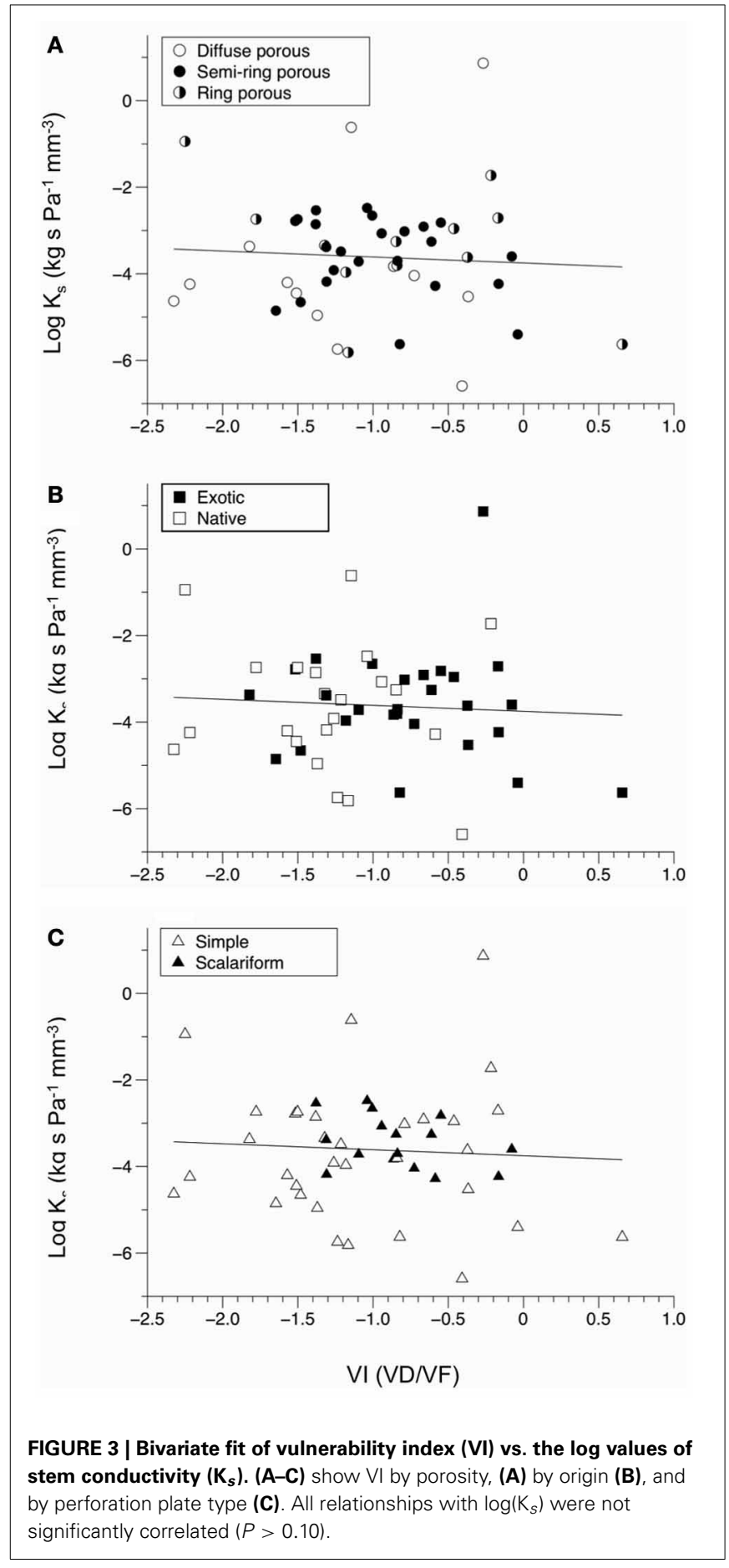

vessel row was $16 \%$, compared with $32 \%$ for genera. Again, origin was the only significant factor in predicting VD $(P<0.0001)$.

\section{VESSEL GROUPINGS}

Approximately $62 \%$ of non-native species had metaxylem, while only $16 \%$ of native species had metaxylem. Comparing the vessel groupings in metaxylem of the non-native species to the few native species that had metaxylem, non-natives had a higher

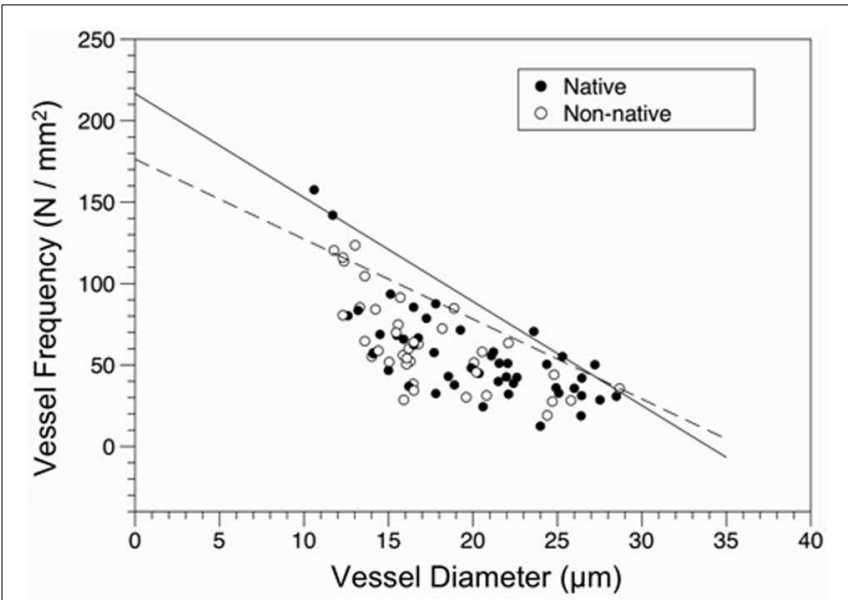

FIGURE 4 | Constraint relationship of vessel frequency (VF, N/mm ${ }^{2}$ ) vs. diameter $(\mathrm{VD}, \mu \mathrm{m})$ for native and non-native species. Solid line represents the fit of the 90th quantile of native species

$(V F=216.674-6.382 \times V D)$, the dashed line for the 90th quantile of non-native species (VF $=176.386-4.909 \times V D)$. Points are shown for origin (Closed circles $=$ native, open circles $=$ non-native).

Table 2 | The effect of vessel development timing, perforation plate type, porosity, origin, and interactions on vessel diameter (VD, $\mu \mathrm{m}$ ).

\begin{tabular}{llcc}
\hline Factor & VD $(\boldsymbol{\mu} \mathbf{m})$ & $\boldsymbol{F}$ & $\boldsymbol{P}$ \\
\hline Vessel row & & 11.664 & $<\mathbf{0 . 0 0 0 1}$ \\
First & $20.003(0.904)$ & & \\
Middle & $20.889(0.904)$ & & \\
Last & $17.215(0.904)$ & & \\
Perforation plate type & & 1.092 & 0.309 \\
Porosity & & 1.035 & 0.364 \\
Perf plate x vessel row & & 2.065 & 0.132 \\
Porosity x vessel row & & 0.648 & 0.630 \\
Origin & & 25.823 & $<\mathbf{0 . 0 0 0 1}$ \\
Native & $21.234(0.839)$ & & \\
Non-native & $17.505(0.882)$ & & \\
Origin $\times$ vessel row & & 0.089 & 0.915 \\
\hline
\end{tabular}

Significant effects are in bold.

number of vessel groupings in the $\geq 5$-vessel grouping class $(P=0.0184$, Table 3$)$.

In the secondary xylem, native species had significantly more vessel groupings in the 3 - $(P=0.0114)$ and 4 -vessel grouping classes $(P<0.0001)$. The proportion of vessel groupings to total vessels was also significantly higher in native species, compared with non-natives, in these two categories $(P=0.0099$ for the 3 -vessel grouping class and $P<0.0001$ for the 4 -vessel grouping class). Thus, the vessel grouping index in native species was higher than that in non-native species $(P=0.0271)$; in other words, non-native species had a higher proportion of solitary vessels in the secondary xylem than native species $(P=0.0277)$.

There was a negative linear relationship between average VD and proportion of solitary vessels to total xylem vessels (Figure 5) 
Table 3 | Vessel grouping in metaxylem and secondary xylem of native and non-native species.

\begin{tabular}{lcrl}
\hline & Native & Non-native & P-value \\
\hline VESSEL GROUPINGS IN METAXYLEM & & \\
Number of 2-vessel groupings & $4.51(0.60)$ & $4.84(0.73)$ & $n . s$. \\
Number of 3-vessel groupings & $3.10(0.48)$ & $3.06(0.42)$ & $n . s$. \\
Number of 4-vessel groupings & $1.71(0.61)$ & $2.16(0.29)$ & $n . s$. \\
Number of >5-vessel groupings & $1.96(0.58)$ & $4.27(0.82)$ & $\mathbf{0 . 0 1 8 4}$ \\
2-vessel grouping (\%) & $21.27(2.94)$ & $19.02(2.94)$ & $n . s$. \\
3-vessel grouping (\%) & $16.92(1.36)$ & $12.08(1.94)$ & n.s. \\
4-vessel groping (\%) & $9.83(1.28)$ & $7.23(0.73)$ & $n . s$. \\
>5-vessel grouping (\%) & $9.69(2.12)$ & $12.08(1.22)$ & $n . s$. \\
Vessel grouping index & $3.14(0.13)$ & $3.44(0.14)$ & $n . s$. \\
Solitary vessels (\%) & $13.97(4.11)$ & $22.80(3.86)$ & $n . s$. \\
VESSEL GROUPINGS IN SECONDARY XYLEM & & \\
Number of 2-vessel groupings & $21.51(2.07)$ & $17.46(2.08)$ & $n . s$. \\
Number of 3-vessel groupings & $4.99(0.45)$ & $3.29(0.42)$ & $\mathbf{0 . 0 1 1 4}$ \\
Number of 4-vessel groupings & $3.30(0.35)$ & $1.29(0.23)$ & $<\mathbf{0 . 0 0 0 1}$ \\
Number of >5-vessel groupings & $3.00(0.44)$ & $2.65(0.85)$ & $n . s$. \\
2-vessel grouping (\%) & $23.72(1.72)$ & $19.70(1.92)$ & $n . s$. \\
3-vessel grouping (\%) & $9.04(0.87)$ & $5.86(0.77)$ & $\mathbf{0 . 0 0 9 9}$ \\
4-vessel groping (\%) & $7.46(0.82)$ & $2.77(0.43)$ & $<\mathbf{0 . 0 0 0 1}$ \\
>5-vessel grouping (\%) & $9.60(2.02)$ & $5.57(1.09)$ & $n . s$. \\
Vessel grouping index & $2.61(0.06)$ & $2.43(0.07)$ & $\mathbf{0 . 0 2 7 1}$ \\
Total solitary vessels (\%) & $51.43(2.98)$ & $60.49(2.52)$ & $\mathbf{0 . 0 2 7 7}$ \\
\hline
\end{tabular}

Significant P-values for the comparisons are in bold; n.s. indicates a non-significant difference.

suggesting that species with smaller vessels tend to have fewer vessel groupings.

There was a decrease in the vulnerability index with increasing percentage of solitary vessels (Figure 6). Specifically, the vulnerability index decreased with decreasing percentage of vessel groupings in the 2, 3, and 4-vessel grouping classes, but not in $\geq 5$-vessel grouping class (Figure 7).

\section{WATER USE EFFICIENCY}

Species represented $68.1 \%$ of the total variability in the model relative to the fixed factors, significantly contributing to differences in WUE $(P<0.0001)$. Light level was the only significant predictor of WUE, increasing 0.3 units per increase in light level (Table 4, $\mathrm{P}<0.0001$ ). Origin had no effect on WUE. All four light levels were significantly different from each other; WUE increased as light levels increased $(P<0.10)$.

\section{DISCUSSION}

Hydraulic contrasts in vessels between native and non-native species have been proposed in a number of recent studies (Pratt and Black, 2006; Caplan and Yeakley, 2010; Cavaleri and Sack, 2010). However, we present results from the first study to examine the direct relationship between xylem vessel anatomical characteristics and water flow across such a large diversity of native and non-native woody shrub species. Contrary to our hypothesis, we found non-native woody species possessed smaller secondary xylem vessels compared

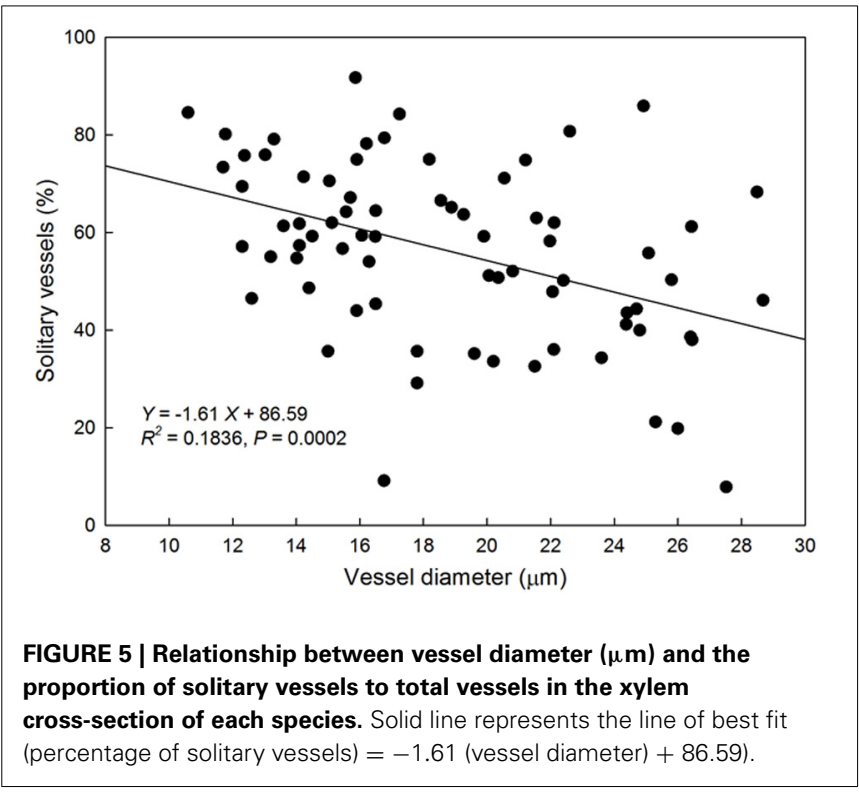

Table 4 | The effect of porosity type, native status, perforation plate type, and light level on water use efficiency (WUE).

\begin{tabular}{lcccc}
\hline Factor & WUE & $\boldsymbol{S E}$ & $\boldsymbol{F}$ & $\boldsymbol{P}$ \\
\hline NATIVE STATUS & & & & \\
Native & 2.75 & 0.12 & 0.3973 & 0.3973 \\
Non-native & 2.89 & 0.11 & & \\
LIGHT LEVEL (PAR $\boldsymbol{\mu}{\mathbf{~ m o l ~} \mathbf{~ m}^{-\mathbf{2}}}^{\mathbf{s}^{\mathbf{- 1}} \text { ) }}$ & & $\mathbf{0 . 0 0 0 1}$ \\
50 & $1.38^{\mathrm{a}}$ & 0.095 & 523.5904 & \\
100 & $2.27^{\mathrm{b}}$ & 0.095 & & \\
300 & $3.58^{\mathrm{c}}$ & 0.095 & & \\
800 & $4.06^{\mathrm{d}}$ & 0.095 & & \\
\hline
\end{tabular}

Significant factors are in bold. Different letters in a column indicate significant differences in WUE between light levels at the $P<0.05$ level.

with native species although the two groups had similar hydraulic conductance (Figures 1, 3). Non-native, fast-growing species are often considered hydraulically efficient in that they exhibit xylem vessel characteristics that confer high water transport and reduced cavitation resistance (Gilbert et al., 2006; Markesteijn et al., 2011). The Hagen-Poiseuille law, which predicts that the hydraulic efficiency of a vessel increases with the fourth power of its diameter (Tyree and Zimmermann, 2002), would suggest that fast-growing non-native species should have wider VD conduits, which would be advantageous for a rapid growth strategy.

No significant differences in WUE efficiency were found between native and non-native species (Table 4, $P=0.3973$ ). WUE has been postulated to be an important factor contributing to success of non-natives (Funk and Vitousek, 2007), yet differences in WUE between non-native and native species is contingent upon growth form and climate (Cavaleri and Sack, 2010). In co-occurring species of the same growth form, there is evidence to suggest that native and non-native species do not differ 
in WUE, since WUE may act in conjunction with variations in other plant traits to weaken or remove competitive advantages (Daehler, 2003; Funk and Vitousek, 2007; McAlpine et al., 2008; Cavaleri and Sack, 2010).

We found a significant positive correlation between xylem area as a percentage of wood area and hydraulic conductivity, which is consistent with Gleason et al. (2012) who found a positive

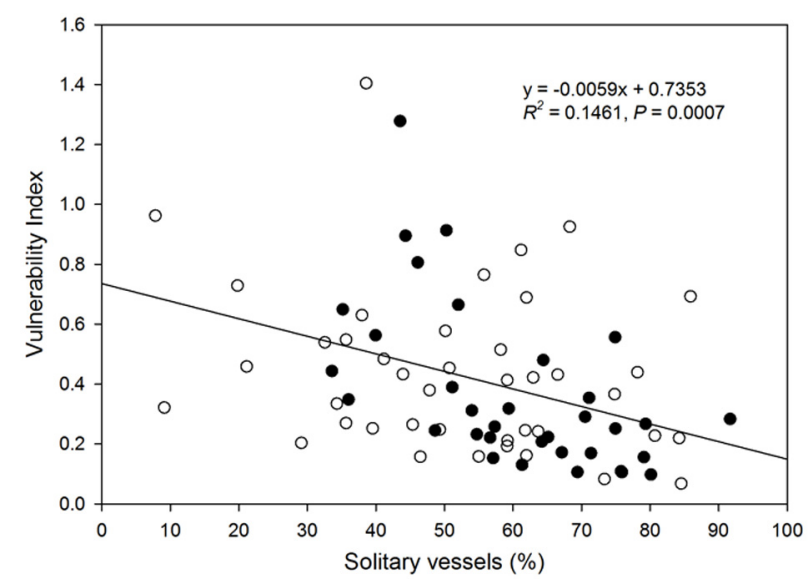

FIGURE 6 | Relationship between vulnerability index and proportion of solitary vessels to total vessels in the xylem cross-section of each species. Filled circles represent native species, and open circles represent native species. Solid line represents the line of best fit (vulnerability index) $=0.0059$ (solitary vessel) +0.7353$)$. correlation between xylem area and stem hydraulic conductivity across 120 Australian woody dicot species. However, there was not a relationship between conductivity and conduit traits of diameter and frequency, potential vulnerability index, and categorical porosity type (Figure 2 ). Since potential vulnerability index was calculated directly from VD, it is unlikely that this measure would relate to $\mathrm{K}_{s}$ given the lack of relationship with VD. There was also no difference in conductivity between simple and scalariform plate types $(P>0.10)$, despite evidence from Christman and Sperry (2010) showing a considerable influence of vessel perforation plate type on xylem flow resistance in scalariform species. This finding may be due to the significant relatedness between individuals, since perforation plate type is conserved within groups of closely related species (Table $\mathbf{1}$ ). The relationship between hydraulic conductivity and resistance to cavitation events is well studied, with numerous findings of a trade-off between safety and efficiency (Pockman and Sperry, 2000; Hacke et al., 2006; Sperry et al., 2008; Markesteijn et al., 2011). The extent of this relationship is highly dependent upon adaptation of the xylem vessels (Markesteijn et al., 2011). A lack of difference in hydraulic conductance and potential vulnerability index in our study suggests that non-native plants do not exhibit a hydraulic advantage over native plants, a similar finding to that of Pratt and Black (2006). However, our lack of difference in hydraulic conductance and potential vulnerability index may be attributed to other anatomical factors such as perforation pits, which may account for $>50 \%$ of total flow resistance of vessel networks depending on number, size, and structure (Wheeler et al., 2005; Choat et al., 2008; Lens et al., 2011) and conduit
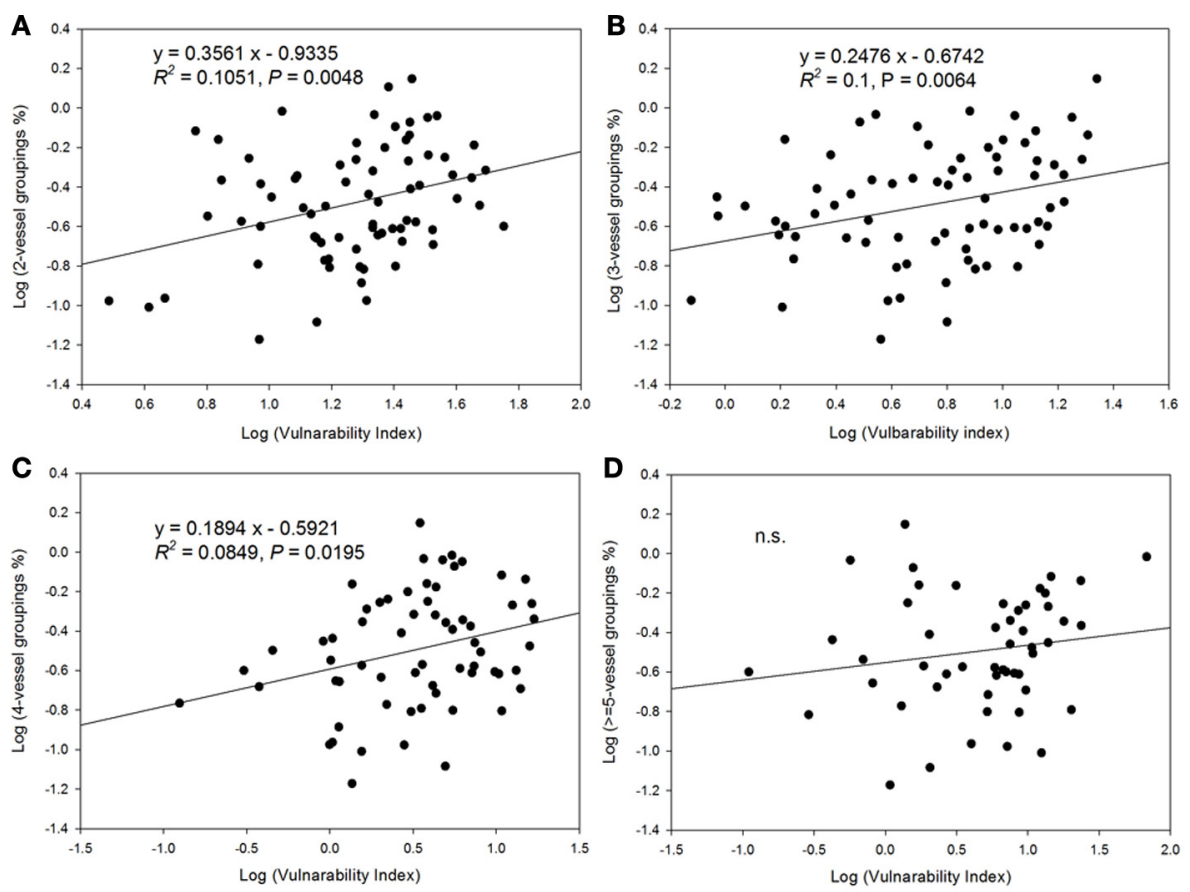

FIGURE 7 | Relationship between vulnerability index and vessel grouping classifications. (A) the relationship with 2-vessel groupings; (B) 3-vessel groupings; (C) 4-vessel groupings; and (D) $\geq 5$-vessel groupings. 
length which is correlated with porosity type and conductivity per xylem cross-sectional area $\left(\mathrm{K}_{X A}\right.$; Zimmermann and Jeje, 1981; Lens et al., 2011). Additionally, our lack of difference may be due to the phylogenetic relationships among the species tested. Recent findings from Markesteijn et al. (2011) indicate that species differences can account for $62-98 \%$ of the variation in vessel traits. In our study, phylogenetic relatedness accounted for $39-68 \%$ of the total variation among traits. Comparing phylogenetic relatedness of native and non-native plants provided more meaningful explanation of invasive traits (McDowell, 2002; Dawson et al., 2011). However, phylogenetic relatedness may constrain morphological and physiological variations between species (Goldberg, 1987), which may explain the lack of difference in vessel traits observed in our study.

Non-native species had much higher $(\geq 5)$ vessel groupings in metaxylem than native species. Metaxylem most likely becomes non-functioning after secondary xylem has developed, but it serves an important function during initial growth as in our species with only 1 year of growth. It is likely that the formation of metaxylem and vessel connectivity play an important role in the high growth rate of many non-native species. Maximum hydraulic conductivity has been found to increase with vessel connectivity (Loepfe et al., 2007). Meanwhile, higher vessel groupings may also increase the vulnerability to cavitation by increasing the probability for the spread of embolism (Loepfe et al., 2007). In contrast to Loepfe et al. (2007), Carlquist (2009), and Lens et al. (2011) stated that vessel grouping would decrease the vulnerability to cavitation since it serves to bypass frequent embolisms by providing alternative routes for water flow. In our study, higher vessel groupings, especially the 2-, 3-, and 4vessel groupings, showed increasing vulnerability to embolism, supporting the Loepfe et al. (2007) model for the potential of vessel connectivity to promote embolism. Interestingly, non-native species also had a higher proportion of small solitary vessels within their secondary xylem, which could partially explain the lack of difference in $K_{s}$ between native and non-native species.

Average xylem vessel size was significantly smaller in nonnative woody shrub species than in native species. In northern temperate deciduous forests, resistance to cavitation is an important feature in freeze tolerance. Davis et al. (1999) suggested a strong correlation between VD and cavitation by freezing, where small-vessel conduits are relatively resistant to cavitation. Thus, the smaller VD in non-native species may increase the competitive advantage of non-native species by allowing a longer growing season through higher resistance to cavitation from late-season freeze events. In fact, recent work by Fridley (2012) has shown that non-native deciduous plants retain leaves longer through the autumn season than related native species thus allowing prolonged growth.

While our study incorporates abroad range of species, our scope is limited to stem hydraulic conductance, which expressed inversely as resistance might account for a fraction of the total hydraulic resistance of a plant from roots to leaves (Tyree and Ewers, 1991; Becker et al., 1999). Root mean VDs were on average $30 \%$ larger than twig vessels in a recent study of tropical trees by Schuldt et al. (2013), indicating an 85\% increase in theoretical hydraulic conductance, as calculated by the Hagen-Poiseuille law. In future work, having a complete hydraulic architecture of non-native plants may better elucidate competitive mechanisms for water transport in non-native species. Moreover, a thorough evaluation of hydraulic conductance throughout an entire growing season is warranted as we suspect that larger differences in $\mathrm{K}_{s}$ may occur earlier in the spring when non-native species have functional metaxylem during shoot elongation.

\section{AUTHOR CONTRIBUTIONS}

Taryn L. Bauerle and Jason D. Fridley designed the experiment. Maria S. Smith carried out the measurements. Maria S. Smith and Jingjing Yin performed the data analysis. Maria S. Smith, Taryn L. Bauerle, Jingjing Yin, and Jason D. Fridley prepared the manuscript.

\section{ACKNOWLEDGMENTS}

We thank Meghan Horne for help with sectioning and embedding tissue samples, Vinay Pagay for running the HPFM and John Zhao for field help.

\section{REFERENCES}

Aref, I. M., Ahmed, A. I., Khan, P. R., El-Atta, H. A., and Iqbal, M. (2013). Drought-induced adaptive changes in the seedling anatomy of Acacia ehrenbergiana and Acacia tortilis subsp raddiana. Trees 27, 959-971. doi: 10.1007/s00468-013-0848-2

Baas, P. (1986). "Ecological patterns of xylem anatomy," in On the Economy of Plant Form and Function, ed T. J. Givinish. (Cambridge: Cambridge University Press), 327-351.

Bauerle, T. L., Centinari, M., and Bauerle, W. L. (2011). Shifts in xylem vessel diameter and embolisms in grafted apple trees of differing rootstock growth potential in response to drought. Planta 234, 1045-1054. doi: 10.1007/s00425011-1460-6

Becker, P., Tyree, M. T., and Tsuda, M. (1999). Hydraulic conductances of angiosperms versus conifers: similar transport sufficiency at the whole-plant level. Tree Physiol. 19, 445-452. doi: 10.1093/treephys/19.7.445

Brodribb, T. J., Holbrook, N. M., and Gutiérrez, M. V. (2002). Hydraulic and photosynthetic co-ordination in seasonally dry tropical forest trees. Plant Cell and Environ. 25, 1435-1444. doi: 10.1046/j.1365-3040. 2002.00919.X

Caplan, J. S., and Yeakley, J. A. (2010). Water relations advantages for non-native Rubus armeniacus over two native ruderal congeners. Plant Ecol. 210, 169-179. doi: 10.1007/s11258-010-9747-4

Carlquist, S. (2009). Non-random vessel distribution in woods: patterns, modes, diversity, correlations. Aliso. 27, 39-58.

Carlquist, S. (1977). Ecological factors in wood evolution: a floristic approach. Am. J. Bot. 64, 887-896. doi: 10.2307/2442382

Cavaleri, M. A., and Sack, L. (2010). Comparative water use of native and invasive plants at multiple scales: a global meta-analysis. Ecology 91, 2705-2715. doi: 10.1890/09-0582.1

Christman, M. A., Sperry, J. S., and Adler, F. R. (2009). Testing the 'rare pit' hypothesis for xylem cavitation resistance in three species of Acer. New Phytologist. 182, 664-674. doi: 10.1111/j.1469-8137.2009.02776.x

Christman, M. A., and Sperry, J. S. (2010). Single-vessel flow measurements indicate scalariform perforation plates confer higher flow resistance than previously estimated. Plant Cell and Environ. 33, 431-443. doi: 10.1111/j.13653040.2009.02094.x

Choat, B., Cobb, A. R., and Jansen, S. (2008). Structure and function of bordered pits: new discoveries and impacts on whole-plant hydraulic function. New Phytol. 177, 608-625. doi: 10.1111/j.1469-8137. 2007.02317.x 
Cochard, H., and Tyree, M. T. (1990). Xylem dysfunction in Quercus: vessel sizes, tyloses, cavitation and seasonal changes in embolism. Tree Physiol. 6, 393-407. doi: $10.1093 /$ treephys/6.4.393

Daehler, C. C. (2003). Performance comparisons of co-occuring native and alien plants: Implications for conservation and restoration. Annu. Rev. Ecol. Evol. Syst. 34, 183-211. doi: 10.1146/annurev.ecolsys.34.011802.132403

Dale, M. P., and Causton, D. R. (1992). The ecophysiology of Veronica chamaedrys, $V$. Montana and V. officinalis. II. The interaction of irradiance and water regime. J. Ecol. 80, 493-504. doi: 10.2307/2260693

Davis, S. D., Sperry, J. S., and Hacke, U. G. (1999). The relationship between xylem conduit diameter and cavitation caused by freezing. Am. J. Bot. 86, 1367-1372. doi: $10.2307 / 2656919$

Davis, M. A., Grime, J. P., and Thompson, K. (2000). Fluctuating resources in plant communities: a general theory of invisibility. J. Ecol. 88, 528-534. doi: 10.1046/j.1365-2745.2000.00473.x

Drenovsky, R. E., Khasanova, A., and James, J. J. (2012). Trait convergence and plasticity among native and invasive species in resource-poor environments. Am. J. Bot. 99, 629-639. doi: 10.3732/ajb.1100417

Dawson, W., Fischer, M., and van Kleunen, M. (2011). The maximum relative growth rate of common UK plant species is positively associated with their global invasiveness. Glob. Ecol. Biogeogr. 20, 299-306. doi: 10.1111/j.14668238.2010.00599.x

Fridley, J. D. (2012). Extended leaf phenology and the autumn niche in deciduous forest invasions. Nature 485, 359-364. doi: 10.1038/nature11056

Funk, J. L., and Vitousek, P. M. (2007). Resource-use efficiency and plant invasion in low-resource systems. Nature 446, 1079-1081. doi: 10.1038/nature05719

Gilbert, B., Wright, S. J., Muller-Landau, H. C., Kitajima, K., and Hernandez, A. (2006). Life history trade-offs in tropical trees and lianas. Ecology 87, 1281-1288. doi: 10.1890/0012-9658(2006)87[1281:LHTITT]2.0.CO;2

Gleason, S. M., Butler, D. W., Zieminska, K., Waryszak, P., and Westoby, M. (2012). Stem xylem conductivity is key to plant water balance across Australian species. Funct. Ecol. 26, 343-352. doi: 10.1111/j.1365-2435.2012.01962.x

Goldberg, D. (1987). Neighborhood competition in an old field plant community. Ecology 68, 1211-1223. doi: 10.2307/1939205

Gonçalves, B., Correia, C., Silva, A., Bacelar, E., Santos, A., Ferreira, H., et al. (2007). Variation in xylem structure and function in roots and stems of scion-rootstock combinations of sweet cherry tree (Prunus avium L.). Trees 21, 121-130. doi: 10.1007/s00468-006-0102-2

Grime, J. P. (2001). Plant Strategies, Vegetation Processes, and Ecosystem Properties. New York, NY: John Wiley \& Sons Ltd.

Grotkopp, E., Rejmanek, M., and Rost, T. L. (2002). Toward a causal explanation of plant invasiveness: seedling growth and life-history strategies of 29 pine (Pinus) species. Am. Nat. 159, 396-419. doi: 10.1086/338995

Hacke, U. G., Sperry, J. S., Pockman, W. T., Davis, S. D., and McCulloh, K. A. (2001). Trends in wood density and structure are linked to prevention of xylem implosion by negative pressure. Oecologia 126, 457-461. doi: 10.1007/ s004420100628

Hacke, U. G., Sperry, J. S., Wheeler, J. K., and Castro, L. (2006). Scaling of angiosperm xylem xtructure with safety and efficiency. Tree Physiol. 26, 689-701. doi: 10.1093/treephys/26.6.689

Jansen, S., Baas, P., Gasson, P., Lens, F., and Smets, E. (2004). Variation in xylem structure from tropics to tundra: Evidence from vestured pits. Proc. Natl. Acad. Sci. 101, 8833-8837. doi: 10.1073/pnas.0402621101

Lens, F., Sperry, J. S., Christman, M. A., Choat, B., Rabaey, D., and Jansen, S. (2011). Testing hypotheses that link wood anatomy to cavitation resistance and hydraulic conductivity in the genus Acer. New Phytol. 190, 709-723. doi: 10.1111/j.1469-8137.2010.03518.x

Loepfe, L., Martinez-Vilalta, J., Piñol, J., and Mencuccini, M. (2007). The relevance of xylem network structure for plant hydraulic efficiency and safety. J. Theor. Biol. 247, 788-803. doi: 10.1016/j.jtbi.2007.03.036

Markesteijn, L., Poorter, L., Bongers, F., Paz, H., and Sack, L. (2011). Hydraulics and life history of tropical dry forest tree species: coordination of species' drought and shade tolerance. New Phytol. 191, 480-495. doi: 10.1111/j.14698137.2011.03708.x

McAlpine, K. G., Linley, J., and Kubien, D. S. (2008). Photosynthesis and water-use efficiency: A comparison between invasive (exotic) and noninvasive (native) species. Austral Ecology 33, 10-19. doi: 10.1111/j.1442-9993. 2007.01784.x
McCulloh, K., Sperry, J. S., Lachenbruch, B., Meinzer, F. C., Reich, P. B., and Voelker, S. (2010). Moving water well: comparing hydraulic efficiency in twigs and trunks of coniferous, ring-porous, and diffuse-porous saplings from temperate and tropical forests. New Phytol. 186, 439-450. doi: 10.1111/j.14698137.2010.03181.x

McCully, M. E., Huang, C. X., and Ling, L. E. C. (1998). Daily embolism and refilling of xylem vessels in the roots of field-grown maize. New Phytol. 138, 327-342. doi: 10.1046/j.1469-8137.1998.00101.x

McDowell, S. C. L. (2002). Photosynthetic characteristics of invasive and non-invasive species of Rubus (Rosaceae). Am. J. Bot. 89, 1431-1438. doi: 10.3732/ajb.89.9.1431

Meinzer, F. C., Clearwater, M. J., and Goldstein, G. (2001). Water transport in trees: current perspectives, new insights and some controversies. Environ. Exp. Bot. 45, 239-262. doi: 10.1016/S0098-8472(01)00074-0

Meinzer, F. C., McCulloh, K. A., Lachenbruch, B., Woodruff, D. R., and Johnson, D. M. (2010). The blind men and the elephant: the impact of context and scale in evaluating conflicts between plant hydraulic safety and efficiency. Oecologia 164, 287-296. doi: 10.1007/s00442-010-1734-x

Pockman, W. T., and Sperry, J. S. (1996). Freezing-induced xylem cavitation and the northern limit of Larrea tridentata. Oecologia 109, 19-27. doi: 10.1007/s004420050053

Pockman, W. T. and Sperry, J. S. (2000). Vulnerability to xylem cavitation and the distribution of Sonoran desert vegetation. Am. J. Bot. 87, 1287-1299. doi: $10.2307 / 2656722$

Pratt, R. B., and Black, R. A. (2006). Do invasive trees have a hydraulic advantage over native trees? Biol. Invasions 8, 1331-1341. doi: 10.1007/s10530-005-0422-y

Ruzin, S. E. (1999). Plant Microtechnique and Microscopy. Oxford: Oxford University Press.

Schuldt, B., Leuschner, C., Brock, N., and Horna, V. (2013). Changes in wood density, wood anatomy and hydraulic properties of the xylem along the rootto-shoot flow path in tropical rainforest trees. Tree Physiol. 33, 161-174. doi: $10.1093 /$ treephys/tps122

Sperry, J. S., Donnelly, J. R., and Tyree, M. T. (1988). A method for measuring hydraulic conductivity and embolism in xylem. Plant Cell Environ. 11, 35-40. doi: 10.1111/j.1365-3040.1988.tb01774.x

Sperry, J. S., Meinzer, F. C., and McCulloh, K. A. (2008). Safety and efficiency conflicts in hydraulic architecture: scaling from tissues to trees. Plant Cell and Environ. 31, 632-645. doi: 10.1111/j.1365-3040.2007.01765.x

Sperry, J. S., Nichols, K. L., Sullivan, J. E. M., and Eastlack, S. E. (1994). Xylem embolism in ring-porous, diffuse-porous, and coniferous trees of Northern Utah and interior Alaska. Ecology 75, 1736-1752. doi: 10.2307/ 1939633

Steppe, K., and Lemeur, R. (2007). Effects or ring-porous and diffuse-porous stem wood anatomy on the hydraulic parameters used in water flow and storage model. Tree Physiol. 27, 43-52. doi: 10.1093/treephys/27.1.43

Taneda, H., and Sperry, J. S. (2008). A case-study of water transport in co-occurring ring- versus diffuse-porous trees: contrasts in water-status, conducting capacity, cavitation and vessel refilling. Tree Physiol. 28, 1641-1651. doi: 10.1093/treephys/28.11.1641

Tyree, M. T., and Ewers, F. W. (1991). The hydraulic architecture of trees and other woody plants. New Phytol. 119, 345-360. doi: 10.1111/j.14698137.1991.tb00035.x

Tyree, M. T., Sinclair, B., Lu, P., and Granier, A. (1993). Whole shoot hydraulic resistance in Quercus species measured with a new high-pressure flowmeter. Annales des sciences forestières 50, 417-423. doi: 10.1051/forest:19930501

Tyree, M. T., Davis, S. D., and Cochard, H. (1994). Biophysical perspectives of xylem evolution - is there a tradeoff of hydraulic efficiency for vulnerability to dysfunction. Iawa J. 15, 335-360.

Tyree, M. T, Patiño, S. Bennink, J., and Alexander, J. (1995). Dynamic measurements of root hydraulic conductivity using a high-pressure flowmeter in the laborartory and field. J. Exp. Bot. 282, 83-94. doi: 10.1093/ jxb/46.1.83

Tyree, M. T., and Zimmermann, M. H. (2002). Xylem Structure and the Ascent of Sap. Berlin: Springer Verlag. doi: 10.1007/978-3-662-04931-0

Wheeler, J. W., Sperry, J. S., Hacke, U. G., and Hoang, N. (2005). Inter-vessel pitting and cavitation in woody Rosaceae and other vesseled plants: a basis for a safety vs. efficiency trade-off in xylem transport. Plant Cell and Environ. 28, $800-812$. 
Woodrum, C. L., Ewers F. W., and Telewski, F. W. (2003). Hydraulic, biomechanical, and anatomical interactions of xylem from five species of Acer (Aceraceae). Am. J. Bot. 90, 693-699. doi: 10.3732/ajb.90.5.693

Zanne, A. E., Westoby, M., Falster, D. S., Ackerly, D. D., Loarie, S. R., Arnold, S. E., et al. (2010). Angiosperm wood structure: global patterns in vessel anatomy and their relation to wood density and potential conductivity. Am. J. Bot. 97, 207-215. doi: 10.3732/ajb.0900178

Zimmermann, M. H. and Jeje, A. A. (1981). Vessel length distribution of some American woody plants. Can. J. Bot. 59, 1882-1892. doi: 10.1139/b81-248

Conflict of Interest Statement: The authors declare that the research was conducted in the absence of any commercial or financial relationships that could be construed as a potential conflict of interest.
Received: 05 September 2013; accepted: 11 November 2013; published online: 28 November 2013.

Citation: Smith MS, Fridley JD, Yin J and Bauerle TL (2013) Contrasting xylem vessel constraints on hydraulic conductivity between native and non-native woody understory species. Front. Plant Sci. 4:486. doi: 10.3389/fpls.2013.00486

This article was submitted to Plant Biophysics and Modeling, a section of the journal Frontiers in Plant Science.

Copyright (C) 2013 Smith, Fridley, Yin and Bauerle. This is an open-access article distributed under the terms of the Creative Commons Attribution License (CC BY). The use, distribution or reproduction in other forums is permitted, provided the original author(s) or licensor are credited and that the original publication in this journal is cited, in accordance with accepted academic practice. No use, distribution or reproduction is permitted which does not comply with these terms. 